\title{
Maximizing the Effectiveness of Sexual and Reproductive Health Funding Provided by Seven European Governments
}

By Sara Seims

Sara Seims is senior advisor for population and reproductive health, David and Lucile Packard Foundation.
The landmark United Nations International Conference on Population and Development (ICPD) took place in Cairo almost 20 years ago. At that time, 180 nations made a commitment to work together and to pay for services to improve the sexual and reproductive health and rights (SRHR) of women and men, particularly those living in the world's poorest countries.

Progress since then has been uneven, and there remains a great deal of room for improvement on SRHR indicators, particularly among the world's poorest women. Currently, one in five women of reproductive age in the developing world-215 million women-have an unmet need for modern contraception. ${ }^{1}$ That is, they are sexually active, able to become pregnant and do not want to give birth in the next two years, but are not using a modern family planning method, and are therefore at risk for unintended pregnancy. Poor women and young women are particularly at risk. Among sexually active women aged 15-19 in Sub-Saharan Africa and South Asia, 68\% have an unmet need for modern methods. ${ }^{2}$ One result of high levels of unmet need is not hard to imagine: Every year, nearly 20 million women have an unsafe abortion. * Eight million of these women experience complications that require significant medical treatment. ${ }^{3}$ Only five million receive the care they need, 70,000 women die, and the deaths and ill health caused by unsafe abortion leave women's families to face great economic and social hardships. Progress made toward strengthening other components of SRHR, for example, by reducing gender-based violence and protecting sexual minorities, also lags far behind the goals set at ICPD.

Despite the good intentions at Cairo, the money to improve SRHR has not been forthcoming. For example, of the estimated $\$ 6.7$ billion needed annually for contraceptives, only $\$ 3.1$ billion has been made available. Furthermore, some funding comes with strings attached. For instance, the United States-the single largest donor for international family planning-is prevented by law from directly addressing the issue of unsafe abortion. This means that scarce U.S. funds are diverted to much more expensive, albeit essential

\footnotetext{
*Abortion is illegal in most developing countries and is thus forced underground, where it is often performed in unsanitary conditions or by untrained providers.

tIn contrast, the United States spends about $0.19 \%$ of its GDP on development assistance (based on 2008 foreign assistance data and GDP in current U.S. dollars, as reported by the Organisation for Economic Co-operation and Development, though domestic polling shows large numbers of people believe we devote as much as $20 \%$ of all government spending to foreign aid.
}

under the circumstances, postabortion care. The United States also does not have an official policy of providing contraceptives to sexually active unmarried young people to help them avoid unplanned pregnancies.

The controversies surrounding abortion and sexual behaviors have made SRHR an easy target for conservative attack. In fact, when the Millennium Development Goals (MDGs) became the globally agreed-upon framework for aid in 2000, the ICPD priorities were excluded. It took an additional five years of hard work by advocates to have the following language added to MDG 5, the goal directed at reducing maternal mortality: "Achieve, by 2015, universal access to reproductive health."

In contrast to some governments, which have exhibited inconsistent support for SRHR issues, seven European countries-Denmark, Finland, Germany, the Netherlands, Norway, Sweden and the United Kingdom-have been steadfast in their commitment to the entire ICPD program, including combating unsafe abortion, providing access to contraceptives for all who need them and protecting sexual minorities, particularly youth. Unfortunately, despite their generosity and progressive policies, conflicts in these countries' development values attenuate the impact of their aid. This Comment will review the ways in which these seven governments provide SRHR aid, discuss the dissonant values and suggest ways in which that dissonance could be alleviated. For women in developing countries who depend on European donors to support SRHR, especially the more controversial elements, such as abortion and services for sexually active youth, improving the effectiveness of these donors' aid is vital.

\section{What Shapes the Donors' SRHR Aid?}

These seven European countries are strong supporters of development aid in general. All have exceeded, reached or pledged to reach the goal of allocating $0.7 \%$ of their gross domestic product (GDP) to development. ${ }^{\dagger} 4$ Although these countries and their respective donor agencies do not have identical philosophies and practices, they share commitment to the following two groups of values.

First, they exhibit a strong national commitment to SRHR and recognize the vital role of civil society in the development process. These countries endorse all major components of SRHR, including sexuality education, access to contraceptives, prevention and treatment of STIs (including HIV), safe abortion, postabortion care, reductions in gender-based violence and protections for sexual minorities. They embrace official policy positions in 
support of programs addressing all of these issues and are willing to express such positions in international forums. In recognition of the role of civil society (NGOs, community groups, media, educational institutions and other nongovernmental entities) in their own countries and in developing countries, they allocate SRHR funds to these groups.

Second, the seven countries are strongly committed to developing-country ownership of development programs and to the autonomy of multilateral United Nations (UN) agencies. These seven governments have long championed the Paris and Accra agreements, ${ }^{5}$ which established that donors should respond to the expressed priorities of developing countries, rather than funding narrowly focused projects reflecting the donors' own agendas. To support developing-country autonomy, these European governments delegate a large proportion of aid decisions to their embassies located in those countries.

These European donors also show respect for the role and autonomy of international agencies, especially the UN development organizations, by providing aid primarily in the form of core support to be spent according to the agencies' priorities. Until recently, these European donors have generally avoided questioning the resource allocation decisions of these UN agencies.*

SRHR-related development assistance was recently assessed in each of the seven donor countries. ${ }^{\dagger}$ These analyses, commissioned by the Hewlett Foundation, took place between May and October 2010. They draw from structured and unstructured interviews with experts from donor agencies, think tanks, NGOs and other interested parties, as well as from analysis of financial and policy reports produced by each of the seven governments. The resulting reports indicate that the two sets of values described above are at times in conflict. This conflict needs to be resolved to ensure that the positive impact on the lives of the world's most vulnerable women is commensurate with the funding provided.

\section{Why Are These Values in Conflict?}

A key conflict sometimes arises between donor governments' support for SRHR and their commitment to developing countries' autonomy in determining how to allocate the health funds they receive. European donor countries earmark only a small proportion of their health funding for SRHR, while allocating the majority of health funds to strengthen health systems in the developing countries in which they work or to provide money to health-related multilateral UN agencies and the Global Fund to Fight AIDS, Tuberculosis and Malaria (GFATM). Because of the value they place on country ownership, the donors are reluctant to impose their SRHR priorities on developingcountry health ministries, beyond promoting the broad aims of the MDGs. Yet, the recipient countries may choose not to fund SRHR or not to give it the priority that these European donors would like. This scenario often plays out in Sub-Saharan Africa, where SRHR programs remain chronically underfunded and poorly staffed, despite acute need. In such cases, continuing high rates of unsafe abortion and gender-based violence, as well as slow progress in improving contraceptive security ${ }^{6}$ demonstrate the insufficient priority some developing countries place on SRHR initiatives.

Contributing to this potential disconnect between funders' intentions and the outcomes their aid achieves is the fact that civil society organizations typically have little or no input in negotiations for support to health systems in developing countries. Instead, such decisions occur among the donor's and the recipient's government officials, sometimes with the assistance of donor governments' own SRHR experts (which helps while programs are being designed and negotiated but is unlikely to advance country ownership in the long term). Experience on the ground has shown that support for SRHR in recipient countries is largely driven by domestic civil society organizations, especially those whose missions include improving women's health and well-being, and not by health and finance ministers, the usual participants. Without civil society's presence, country ownership is really only government ownership.

The United Nations Population Fund (UNFPA) is increasingly becoming involved in health-sector support and could help bridge the gap between developing-country governments and SRHR civil society organizations. There are encouraging examples of where SRHR has been given priority in health funding programs, and much can be gained from expanding these positive experiences to other countries. One such instance is in Malawi, where NGOs and UNFPA actively participated in designing a health program that included SRHR as a significant component. ${ }^{7}$ Recent proposals submitted to the Global Fund to Fight AIDS, Tuberculosis and Malaria (GFATM) also illustrate good ways to integrate reproductive health with HIV prevention. For example, in Ghana, almost half of health funds were allocated to reproductive health-related services and supplies. NGOs, such as the Planned Parenthood Association of Ghana, played a crucial role. ${ }^{8}$

The country studies also documented that those who are included in funding decisions may not prioritize or be well-informed about SRHR. Donor countries' embassy staff located in developing countries play a large role in negotiating with the ministries of health about how to allocate recipient countries' health resources. However, the SRHR expertise of embassy staff varies greatly among these European donors. In fact, some of the country analyses revealed that their embassy staff were uncomfortable talking about SRHR-related topics, despite the reputation of their countries for progressive attitudes on these mat-

\footnotetext{
*The UK aid agency, the Department for International Development, recently evaluated the effectiveness of the multilaterial agencies it supports. It is too soon to tell how this review and other such evaluations will influence European funders.

†The seven country reports can be found at <www.dsw-online.org/ odastudies $>$.
} 
ters. This means that strong advocacy for allocating health resources toward the achievement of the ICPD and the portion of MDG 5 that calls for universal access to reproductive health rarely takes place.

In the country analyses, experts who had worked in developing countries reported that ministries of health, with some exceptions, have demonstrated little interest in taking up the SRHR mantle and may be especially unmotivated to address the more controversial elements. Ministries of health are not typically expected to report on SRHR progress; therefore, such issues tend not to be prioritized. An essential step toward resolving this problem would be to involve SRHR experts from civil society, along with donor embassy staff and the developing country government, in the design of programs to strengthen health systems.

Many of the interviewees from these European countries noted that the staff of their donor agencies were themselves significant but underused resources, who could and should play a more interactive role by encouraging the multilateral organizations that they fund to focus more on SRHR. Interviews with the donors revealed a reluctance to dictate to these organizations how they should allocate the money given to them. However, at least some of these multilateral organizations may place a higher priority on SRHR if the donor countries urge them to do so.

\section{Levels of Funding for SRHR}

Value conflicts in the health development strategies of these seven European donor countries have become particularly apparent during the worldwide economic slowdown. At a time when taxpayers are experiencing cuts in domestic programs, all government expenditures for development assistance are under special scrutiny. Therefore, the aid community is asking for tangible evidence that its funding is actually producing positive results for the general populace in the target countries.

To effectively track funding and measure its results, it is important to know how much aid is actually allocated to SRHR. However, it is impossible to know how much money each of these seven donor countries provides to SRHR in total, let alone the level of support to its individual components. There are three major reasons for this.

First, donor countries' reports of their aid outlays are often unclear or incomplete. Aid is classified according to the criteria determined by the Development Assistance Committee of the Organisation for Economic Co-operation and Development (OECD) into categories that combine HIV/AIDS with reproductive health, and the methodology for disaggregating this information is not standardized. Thus, countries report on their aid outlays using different methods, making it difficult to understand what is included under the OECD categories. This is further complicated by the difficulty some European donors have in reporting on their health assistance at the country level. For example, Germany and Norway were unable to provide much information about the total amount of health funding they pro- vide to each developing country, let alone how these health funds are allocated among the components of SRHR.

Second, these European donors expect that some of the support they provide to strengthen health sectors will be allocated by the developing-country governments to SRHR. However, rarely are there mechanisms in place to accurately determine whether that happens. Therefore, it is also impossible for these donors to track how much of their health-sector support goes to any individual component of SRHR, such as reducing unmet need for contraception, providing safe abortion or combating genderbased violence.

Third, significant funding is channeled to multilateral organizations (such as UN agencies) and to global health NGOs, but the allocation of funds is also not tracked in a way that shows how much goes to SRHR. This is because the donors do not require that this be done and because these agencies also tend to use the OECD categories.

The least ambiguous indication of current investments is the level of support given to SRHR-focused international NGOs, such as the International Planned Parenthood Federation (IPPF) or Marie Stopes International, or to UNFPA. In 2008-2009, the seven European donor countries provided less than $\$ 450$ million to UNFPA, IPPF and other NGOs with SRHR at their core (Table 1). Funding to SRHR-specific organizations accounted for between $7 \%$ and $43 \%$ of the health aid provided by each of the European donors. These same countries provided a total of $\$ 2.4$ billion (about five times as much) to four closely related international agencies (WHO, UNAIDS, UNICEF and the Global Fund). These organizations give higher priority to broad health goals than to the core elements of SRHR.

Although no accurate statement can be made about what proportion of health-sector support funds are used for SRHR, it is clear that support to health systems offers enormous opportunities to improve SRHR. Because the amount of money that some of the European donors provide to strengthen health systems is larger than the amount that they earmark specifically for SRHR, many additional resources could be made available if some proportion of general health funds were allocated for SRHR and if this allocation were monitored carefully.

\section{Increasing the Amount and Impact of SRHR Aid}

The seven country reports detail recommendations from interviewees about how to raise more funds for SRHR and how to increase the effectiveness with which these resources are used. The following recommendations are relevant to all or most of the donor countries and received the highest rankings among the interviewees at a recent meeting in London. Greater detail and context is provided in the individual country reports.

- Increase the voice of civil society in the design and implementation of programs to strengthen the health sector. Meeting participants offered the Global Fund as a model of an agency that successfully includes NGOs, academics and 
other nongovernment stakeholders in decisions about resource allocation. Other multilateral agencies have much to learn from this good example. All who suggested such an integrated approach to decision making acknowledged that investments would be needed to help civil society organizations become stronger and more effective advocates for SRHR. This is easier said than done, since currently there is no targeted funding mechanism to develop the capacities of civil society organizations for this purpose. Many of the experts interviewed believed that the Maputo Accord* is underused and could provide an excellent basis for civil society organizations to increase their governments' commitment to SRHR.

- Enhance the visibility and impact of UNFPA. UNFPA is the one UN agency devoted to the ICPD, and it receives almost $80 \%$ of the SRHR-earmarked funds from the seven European donors. All the country reports recognized the agency's difficult mandate and its importance to the field. Given the rapidly changing donor landscape in global health, an increased need to demonstrate impact and the continuing political sensitivities around SRHR, many experts reported that they would like to see UNFPA do more work on setting norms and policies and less work on implementing services. Many interviewees recommended that UNFPA continue its valuable role in providing contraceptive commodities. There was a widespread wish to more easily track resource flows within UNFPA and to better understand the impact of the agency's work.

- Identify ways to better assess the impact of aid, and use these to guide health investments. There was almost universal recognition among experts interviewed for the country analyses of the need for improved ways of measuring aid effectiveness. They pointed out that progress toward broad, long-term aims, such as those articulated in the ICPD agenda and the MDGs, cannot be tracked solely by long-term national measures, such as reduced maternal mortality. Such measures do not provide the level of detail needed in the short and medium term for making necessary improvements to SRHR services. Furthermore, SRHR agencies tend to employ mostly input measures-such as the number of people trained or the number of contraceptive clinic visits made-and these measures do not provide information about effectiveness. New measures are needed to make it possible to link the investments of an individual funder with progress toward clearly defined goals and to properly assess how much progress is made. Interviewees also indicated that existing measures could be used more effectively to track the impact of aid in ways that could be helpful to program implementers.

UNFPA could play a valuable leadership role in this process. Once better measures have been identified and agreed upon, civil society in developed and developing countries can help ensure that these are monitored carefully.

*In 2006, at a special session of the African Union, ministers of health met in Maputo, Mozambique, and called for universal access to sexual and reproductive health services in Africa.
TABLE 1. Seven countries' health funding to selected international organizations (in US\$ millions), 2008-2009

\begin{tabular}{|c|c|c|c|c|c|c|c|}
\hline Focus of funding & Denmark & Finland & Germany & $\begin{array}{l}\text { Nether- } \\
\text { lands }\end{array}$ & Norway & Sweden & $\begin{array}{l}\text { United } \\
\text { Kingdom }\end{array}$ \\
\hline \multicolumn{8}{|l|}{$\mathrm{SRHR}^{*}$} \\
\hline UNFPA & 35 & 28 & 26 & 83 & 65 & 62 & 31 \\
\hline IPPF & 7 & 1 & 8 & 14 & 6 & 13 & 12 \\
\hline $\begin{array}{l}\text { Other SRHR- } \\
\text { focused NGOs }\end{array}$ & 5 & 2 & 7 & 12 & 3 & 10 & 5 \\
\hline \multicolumn{8}{|l|}{ AIDS } \\
\hline UNAIDS & 7 & 12 & 3 & 47 & 56 & 39 & 16 \\
\hline GFATM & 29 & 5 & 262 & 79 & 75 & 132 & 78 \\
\hline \multicolumn{8}{|l|}{ General health } \\
\hline WHOt & 7 & 2 & 28 & 25 & 42 & 34 & 20 \\
\hline UNICEF & 32 & 22 & 16 & 7 & 159 & 156 & 25 \\
\hline $\begin{array}{l}\text { National NGOs } \neq \\
\text { \% of health funding } \\
\text { earmarked for }\end{array}$ & 65 & u & 245 & 34 & 108 & u & 176 \\
\hline SRHR-focused NGOs & 25 & 43 & 7 & 36 & 13 & 19 & 13 \\
\hline
\end{tabular}

Notes: Data were obtained by the experts who wrote the country reports on which this Comment is based.u=unknown. *Funding to NGOs that focus explicitly on SRHR. Includes core support and funds to the Human Reproduction Program. ₹Includes NGOs that are not focused on SRHR but sometimes perform SRHR-related work (e.g., faith-based organizations, Doctors Without Borders).

- Allocate more resources for special innovative approaches. Some of the most effective SRHR programming is supported by discretionary funds managed from the headquarters of the donor agencies. The Safe Abortion Action Fund, initiated by the UK Department for International Development and cofunded by Norway, provides a good model of innovation in that it has an external board of experts, is transparent about the criteria it uses to assess proposals and has provided funds to community-level organizations, thereby increasing local access to safe abortion. Many interviewees for the country reports recommended that donors increase the amount of money allocated for such special initiatives.

- Improve understanding of the economic benefits of achieving better health for women. More data are needed to document the cost-effectiveness of investing in women's health, and some experts recommended that donor governments provide the funds to collect this information.

- Strengthen SRHR capabilities at the embassy level. Donor countries should be well-equipped to negotiate for the inclusion of SRHR issues in negotiations about health-sector support. These donors should also invest in improving the SRHR expertise within developing-country ministries of health and among district health staff. A practical and costeffective solution for strengthening embassies' SRHR expertise may be to utilize consultants from NGOs.

\section{CONCLUSION}

Together, Denmark, Finland, Germany, the Netherlands, Norway, Sweden and the United Kingdom have proven to be valuable champions for SRHR: They are not only willing to talk about needs in this area, but they commit substantial funds to meeting them. But to maximize their impact, these donor countries need to recognize that some of their values, worthy as they are, attenuate the effectiveness of their aid in advancing SRHR. It is neither appropriate that these values be rejected nor likely that they will 
be. Rather, it is critical to find and advance approaches and mechanisms that improve effectiveness while honoring the spirit of these values.

Implementing the above recommendations would be a good start toward improving the effectiveness of these donors' SRHR investments. For many of these recommendations, political will is as important as additional resources. Unless these steps are taken, the strong cultural value that the populations of these countries place on SRHR will not be adequately represented in their development programs and will therefore not make as much difference in recipient countries as their governments and taxpayers might reasonably expect.

\section{REFERENCES}

1. Singh S et al., Adding It Up: The Costs and Benefits of Investing in Family Planning and Maternal and Newborn Health, New York: Guttmacher Institute and United Nations Population Fund, 2009.

2. Guttmacher Institute and International Planned Parenthood Federation (IPPF), Facts on the sexual and reproductive health of adolescent women in the developing world, In Brief, New York: Guttmacher Institute; and London: IPPF, 2010.

3. Singh S et al., Abortion Worldwide: A Decade of Uneven Progress, New York: Guttmacher Institute, 2009.

4. United Nations Millenium Project, The 0.7 percent target: an indepth look, 2006, <http://www.unmillenniumproject.org/press/ 07.htm>, accessed July 6, 2011.
5. Organisation for Economic Co-operation and Development, The Paris Declaration on Aid Effectiveness and the Accra Agenda for Action, 2008, <http://www.oecd.org/dataoecd/30/63/43911948.pdf>, accessed July 6, 2011.

6. USAID Deliver Project, Measuring Contraceptive Security Indicators in 36 Countries, Arlington, VA: USAID, 2010.

7. Pearson M, Impact Evaluation of the Sector Wide Approach (SWAp), Malawi, Final Report, London: UK Department for International Development, 2010

8. Larson E, Population Action International, personal communication, Aug. 9, 2011

\section{Acknowledgments}

This Comment is based on a summary, written by the author, of seven country reports on European donor funding for sexual and reproductive health and rights prepared by Berit Austveg, Norwegian Board of Health Supervision; Frans Baneke and Wouter Meijer, formerly of the World Population Foundation; David Daniels and Rolla Khadduri, MannionDaniels; Catherina Hinz and Matthias Wein, German Foundation for World Population; Birte Holm Sorensen, independent consultant; Riikka Shemeikka, Population Research Unit, University of Helsinki; and Sarah Thomsen, Karolinska Institute. The author would like to thank Paul Rosenberg of the Hewlett Foundation and Rolla Khadurri of MannionDaniels for their first-rate research assistance and Paul Clermont for his insightful comments and writing suggestions.

Author contact: sara.seims@gmail.com 